\title{
Article \\ Dendrimer Anion-Exchange Stationary Phase for Separation of Oligonucleotides
}

\author{
Sylwia Studzińska *(D), Szymon Bocian (1), Anna Kilanowska and Bogusław Buszewski (
}

Citation: Studzińska, S.; Bocian, S.; Kilanowska, A.; Buszewski, B. Dendrimer Anion-Exchange Stationary Phase for Separation of Oligonucleotides. Molecules 2022, 27, 1491. https://doi.org/10.3390/ molecules27051491

Academic Editor: Ecaterina Stela Dragan

Received: 20 January 2022

Accepted: 20 February 2022

Published: 23 February 2022

Publisher's Note: MDPI stays neutral with regard to jurisdictional claims in published maps and institutional affiliations.

Copyright: (C) 2022 by the authors. Licensee MDPI, Basel, Switzerland. This article is an open access article distributed under the terms and conditions of the Creative Commons Attribution (CC BY) license (https:// creativecommons.org/licenses/by/ $4.0 /)$.
Chair of Environmental Chemistry and Bioanalytics, Faculty of Chemistry, Nicolaus Copernicus University in Torun, 7 Gagarin Str., 87-100 Toruń, Poland; bocian@chem.umk.pl (S.B.); ania.kaczmarkiewicz@gmail.com (A.K.); bbusz@chem.umk.pl (B.B.)

* Correspondence: kowalska@chem.umk.pl; Tel.: +48-56-6114753; Fax: +48-56-6114837
Keywords: oligonucleotide; dendrimer stationary phase; ion-exchange chromatography; separation; interaction

\section{Introduction}

Oligonucleotides are compounds built of many nitrogen bases, sugars (ribose or deoxyribose), and phosphate groups [1]. Their structure consists of nucleotides bounded by a phosphodiester bond in a single strand. Consequently, oligonucleotides are polar, negatively charged compounds with multiple charges derived from phosphate groups [2]. Through inter-molecular self-complementarity structures or intra-molecular structures, they may form hairpin loops. Oligonucleotides are used in many research areas, including as primers in polymerase chain reactions, as probes for DNA sequencing, for the characterization and tracking of nucleic acids in biological systems, and as therapeutics in antisense and gene therapy [1-4].

It is necessary to study oligonucleotide analysis, especially in impurity determination, degradation, or biotransformation product analysis [5]. Separation techniques are mainly used to separate and determine oligonucleotides $[5,6]$. The two most popular analytical tools are ion-pair liquid chromatography and ion-exchange chromatography [6-8]. In the first technique, the amines are used as mobile phase additives. This increases the selectivity but, in some cases, reduces the sensitivity [6]. Similar separation selectivity may be obtained in ion-exchange chromatography, where the retention is based on electrostatic interactions between the negatively charged oligonucleotide and positively charged stationary phase surface [7-11]. The utilization of anion-exchange chromatography allows an elevated temperature or $\mathrm{pH}$ to be employed to control oligonucleotides' separation selectivity by producing fully or partially denaturing conditions [8]. Adsorbents with quaternary ammonium ligands are widely used as stationary phases. Different lengths of alkyl chains can be bounded to the quaternary 
nitrogen atom-usually short ones such as trimethylamine or diethylmethylamine [8-11]. They were successfully applied to separate unmodified, single-stranded OGNs and modified oligonucleotides but some disadvantages were noticed-for example, a lengthy analysis time or insufficient separation [9-11]. Therefore, chromatographic methods of oligonucleotide analysis need improvements, such as proper, careful mobile phase composition changes or the synthesis of new and alternative stationary phases and their application.

Dendrimer stationary phases are a unique separation material for ion-exchange chromatography. Such materials may be synthesized on the polymer support or inorganic materials, e.g., silica gel [12,13]. Silica gel ensures rapid mass transfer, good loadability, and high reproducibility. Unfortunately, silica reveals limited stability in the $\mathrm{pH}$ range $2-10[12,13]$. One of the newest methods of stationary phase preparation with quaternary ammonium groups is the methodology introduced by Pohl and his co-workers [14,15]. A hyperbranched anion-exchange polymer stationary phase is created during the synthesis, containing quaternary ammonium, tertiary, and secondary amine groups. Quaternary ammonium groups possess a positive charge in the $\mathrm{pH}$ range 1-14 [14-18]. Thus, they are strong anion exchangers. On the other hand, tertiary, secondary, and primary amino groups can be positively charged below $\mathrm{pH}$ around 9. As a result, the ion-exchange capacity of the dendrimer anion exchanger may be controlled during the synthesis and analysis by changing the $\mathrm{pH}$ of the mobile phase [14-18].

Dendrimer anion exchangers may be applied to separate inorganic anions and nucleotides [16-20]. Considering the properties of dendrimer anion exchangers described in the literature, it seems reasonable to use them to separate oligonucleotides. Hence, the goal of this study was to apply a series of dendrimer anion exchangers with a different number of bonded layers for the separation of oligonucleotides using various mobile phases. This study aimed to determine how useful dendrimeric stationary phases will be in analyzing oligonucleotides.

\section{Results and Discussion}

\subsection{Stationary Phase Characterization}

In this study, four different chromatographic stationary phases were applied. These materials contained one, two, three, and four bonded anion exchange layers. The exemplary structure is presented in Figure 1 and the elemental composition of the dendrimer-bonded materials is shown in Table 1.

Table 1. Elemental composition of prepared series of anion exchangers.

\begin{tabular}{cccc}
\hline $\begin{array}{c}\text { Number of } \\
\text { Reaction Cycles }\end{array}$ & Nitrogen Content (\%) & Carbon Content (\%) & Hydrogen Content (\%) \\
\hline 1 & 1.72 & 10.63 & 1.87 \\
\hline 2 & 1.78 & 12.67 & 2.19 \\
\hline 3 & 1.82 & 14.42 & 2.45 \\
\hline 4 & 1.88 & 16.45 & 2.80 \\
\hline
\end{tabular}

It is essential to underline that the carbon, nitrogen, and hydrogen content increases with the reaction cycles. However, the increase is lower, as expected from the dendrimer structure. This confirms that the dendrimer structure is not ideal, and not all nitrogen atoms react to obtain quaternary ammonium salts. It results from steric hindrance during the further steps of modification. Each reaction step makes the structure of ligands denser, which hampers the reaction and penetration of analytes into ligands during the separation procedure [16-18]. 


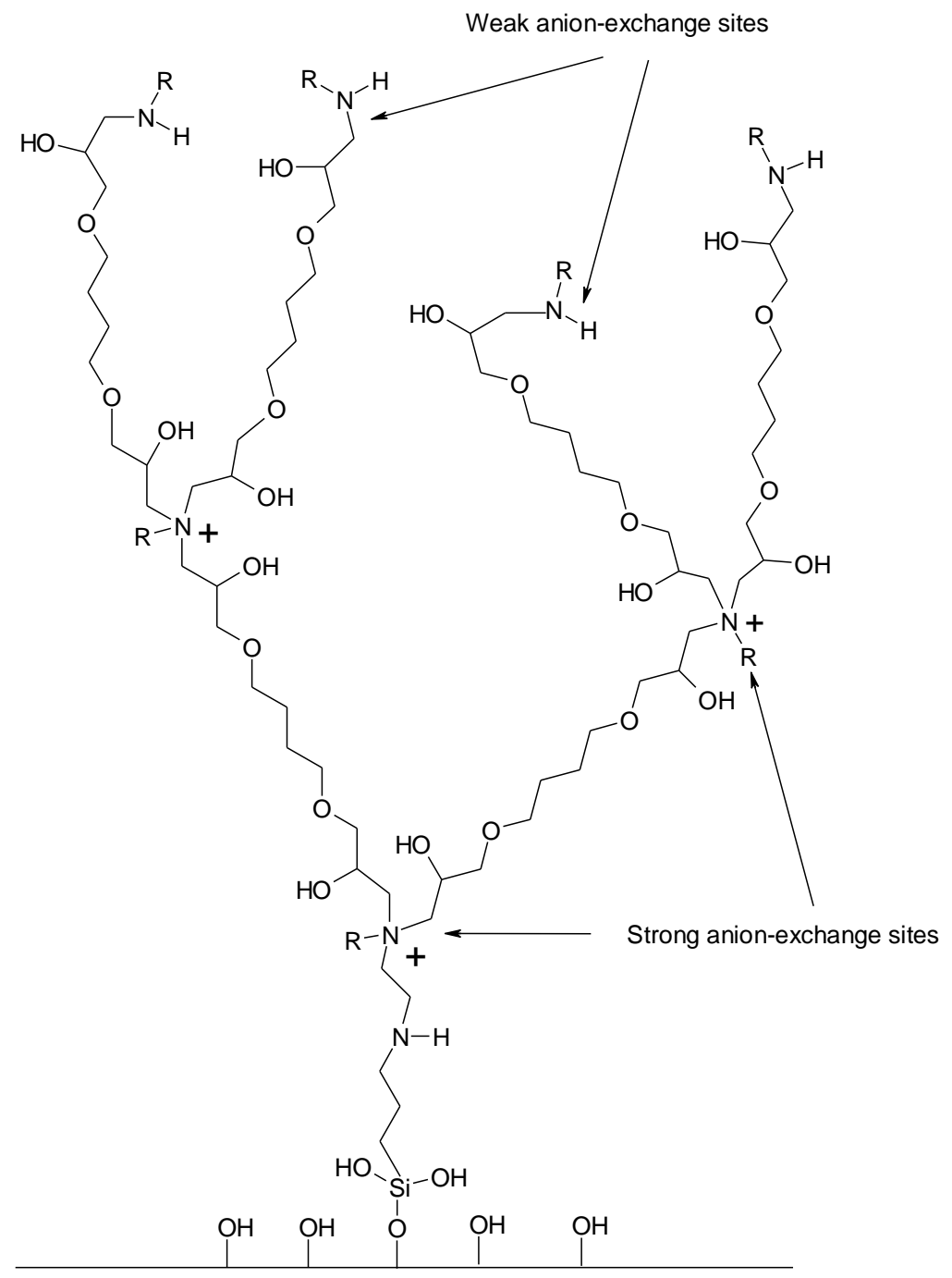

Figure 1. Schematic structure of dendrimer anion exchanger obtained after two reaction cycles.

2.2. The Influence of the Salt in the Mobile Phase on Oligonucleotide Retention

The sequences and molecular masses of the oligonucleotides tested during the study are presented in Table 2.

Table 2. Sequences and molecular masses of oligonucleotides used in the present study.

\begin{tabular}{ccccc}
\hline Shortcut & Sequence $\left(\mathbf{5}^{\prime} \rightarrow \mathbf{3}^{\prime}\right)$ & Modification & $\begin{array}{c}\text { Number of } \\
\text { Nucleotides }\end{array}$ & $\begin{array}{c}\text { Molecular } \\
\text { Mass (Da) }\end{array}$ \\
\hline OL1 & GCCCAAGCTGGCATCCGTCA & - & 20 & 6063 \\
\hline OL2 & GCCCAAGCTGGCATC & - & 15 & 4538 \\
\hline OL3 & GCCCAAGCTG & - & 10 & 3013 \\
\hline OL4 & GCTAGCTAGCTAGCTAGCTA & - & 20 & 6117 \\
\hline OL5 & GCTAGCTAGCTAGCT & - & 15 & 4568 \\
\hline OL6 & GCTAGCTAGC & - & 10 & 3028 \\
\hline PS & GCTAGCTAGCTAGCTAGCTA & phosphorothioate & 20 & 6368 \\
\hline ME & GCTAGCTAGCTAGCTAGCTA & 2 '-O-methyl & 20 & 6622 \\
\hline MOE & GCTAGCTAGCTAGCTAGCTA & $2^{\prime}$-O-methoxyethyl & 20 & 7657 \\
\hline
\end{tabular}


The impact of salt type in the mobile phase on the retention of the tested oligonucleotides was studied. Two inorganic salt solutions, as well as two organic salts, were selected. The results obtained for one of the stationary phases are presented in Table 3.

Table 3. The oligonucleotide retention factor $(k)$ and asymmetry factor $\left(\mathrm{f}_{\mathrm{AS}}\right)$ values were obtained for the dendrimeric stationary phase after three reaction cycles and various aqueous solutions of salts in mobile phases (without $\mathrm{pH}$ correction). Elution conditions: $0 \mathrm{~min}-0.125 \mathrm{M}$ of salt, $5 \mathrm{~min}-0.4 \mathrm{M}$ of salt, $15 \mathrm{~min}-0.4 \mathrm{M}$ of salt.

\begin{tabular}{ccccccccc}
\hline \multirow{2}{*}{ Oligo } & \multicolumn{7}{c}{$k \pm \mathbf{S D}$} \\
\cline { 2 - 9 } & $\mathbf{N a C l}$ & $\mathbf{f}_{\text {AS }}$ & $\mathbf{N a C l O}_{4}$ & $\mathbf{f}_{\text {AS }}$ & $\mathbf{C H}_{3} \mathbf{C O O N H}_{4}$ & $\mathbf{f}_{\text {AS }}$ & $\mathbf{H C O O N H}_{4}$ & $\mathbf{f}_{\text {AS }}$ \\
\hline OL1 & $5.05 \pm 0.04$ & 1.1 & $1.35 \pm 0.07$ & 1.3 & $7.30 \pm 0.09$ & 1.7 & $8.53 \pm 0.08$ & 1.7 \\
\hline OL2 & $4.74 \pm 0.00$ & 0.9 & $1.13 \pm 0.02$ & 1.1 & $6.75 \pm 0.05$ & 1.5 & $8.25 \pm 0.07$ & 1.7 \\
\hline OL3 & $4.49 \pm 0.06$ & 0.9 & $0.68 \pm 0.03$ & 1.1 & $6.19 \pm 0.02$ & 1.6 & $7.09 \pm 0.04$ & 1.8 \\
\hline OL4 & $4.91 \pm 0.02$ & 1.0 & $1.25 \pm 0.06$ & 1.4 & $7.13 \pm 0.02$ & 1.6 & $6.72 \pm 0.04$ & 1.5 \\
\hline OL5 & $4.68 \pm 0.04$ & 1.2 & $0.57 \pm 0.02$ & 1.3 & $6.59 \pm 0.02$ & 1.7 & $6.38 \pm 0.01$ & 1.5 \\
\hline OL6 & $4.58 \pm 0.01$ & 1.1 & $0.69 \pm 0.03$ & 1.4 & $5.50 \pm 0.07$ & 1.5 & $6.56 \pm 0.00$ & 1.6 \\
\hline PS1 & - & & - & & $7.08 \pm 0.02$ & 1.7 & $6.75 \pm 0.11$ & 1.5 \\
\hline ME & $5.82 \pm 0.03$ & 1.2 & $3.70 \pm 0.02$ & 1.2 & $6.62 \pm 0.07$ & 1.5 & $6.71 \pm 0.09$ & 1.6 \\
\hline MOE & $4.87 \pm 0.02$ & 1.0 & $1.36 \pm 0.03$ & 1.2 & $6.35 \pm 0.02$ & 1.7 & $6.80 \pm 0.15$ & 1.7 \\
\hline- not measured. & & & & & & & &
\end{tabular}

The highest $k$ values were determined for ammonium acetate and ammonium formate. This effect is related to the lower elution strength of organic salts in ion-exchange chromatography, resulting from their lower affinity to the anion-exchange site. A significant peak asymmetry was noticed for both salts ranging between 1.5 and 1.8. In consequence, ammonium formate and acetate were excluded from further studies. The greatest elution strength was observed for sodium perchlorate (Table 3). Unfortunately, it provides poor peak shapes of oligonucleotides. Based on the retention factors and peak symmetry, sodium chloride was chosen as a mobile phase component.

\subsection{The Impact of the Length, Sequence, and Modification of Oligonucleotides on Their Retention on Dendrimer Stationary Phases}

Another effect observed during the study was related to the oligonucleotides' sequence and length. An increase in $k$ values was noticed together with the sequence length (Tables 2 and 3). However, in some cases, the difference between $k$ values was not significant, despite differences in sequence length, e.g., OL5 and OL6 for $\mathrm{NaClO}_{4}$ and OL4 and OL5 for $\mathrm{HCOONH}_{4}$. This was probably a consequence of the observed peak asymmetry, influencing the integration and retention time determination. Other trends were observed when using inorganic salts as mobile phases. These were related to the higher strength of electrostatic interactions with the stationary phase surface. As the number of nucleotides building the oligonucleotide increases, negatively charged phosphate groups also increase. Therefore, the resultant negative charge of the oligonucleotide increases simultaneously, which causes greater interaction with the positively charged quaternary ammonium groups at the stationary phase surface. This effect appears to be sequence-independent (e.g., for OL1 and OL4, for OL2 and OL5, OL3, and OL6).

In most cases, the $k$ values are very similar (Table 3). Therefore, it may be concluded that the main impact on the retention of oligonucleotides on an anion exchanger is the electrostatic interactions, consistent with the theory of ion chromatography. It also shows that dendrimer stationary phases can be used to separate oligonucleotides differing in length (contaminants such as shortmers and longmers, or simple metabolites). Unfortunately, our study did not prove that dendrimeric stationary phases allow the separation of 
oligonucleotides differing by only one nucleotide in the sequence, e.g., 20-mer and 19-mer. Moreover, they cannot be used for studies of sequential isomers or isobaric metabolites because the structural selectivity is neglectable.

Oligonucleotides whose sequences were modified within each phosphate group (PS) or each ribose (ME and MOE) were also used in this study (see Table 2). They had sequences analogous to oligonucleotide OL4 (Table 2). Therefore, it was possible to compare the effect of modification type on the retention of the oligonucleotides analyzed using dendrimer stationary phases in ion-exchange chromatography mode. Based on the data summarized in Table 3, it can be concluded that, for $\mathrm{CH}_{3} \mathrm{COONH}_{4}$ and $\mathrm{HCOONH}_{4}$, the $k$ values were comparable for OL4, PS1, ME, and MOE. This indicated that, for organic salts, the modification of the oligonucleotide has no effect on its retention. If the oligonucleotides are of the same length, the $k$ values are similar. The unmodified OL4 had similar retention to the 2'-O-methoxyethyl-modified oligonucleotide MOE. Higher $k$ values were observed for the oligonucleotide with 2'-O-methyl modification in the ribose moiety (ME) (Table 3). Such an effect probably indicates that hydrophobic interactions also impacted the oligonucleotides' retention at the dendrimer stationary phase. Using inorganic salts in the mobile phases, we can distinguish oligonucleotides with the same sequence and length but different types of modification, but this applies only to 2'-O-methyl modification.

\subsection{The Influence of Mobile Phase $p H$ on Oligonucleotide Retention at the Dendrimer Stationary Phase}

The effect of sodium chloride solution ( $\mathrm{pH} 4.5,6.9$, and 8.5) on oligonucleotide retention was tested. The results show that as the $\mathrm{pH}$ value of the salt increased, the retention rates of all tested oligonucleotides decreased (Figure 2).

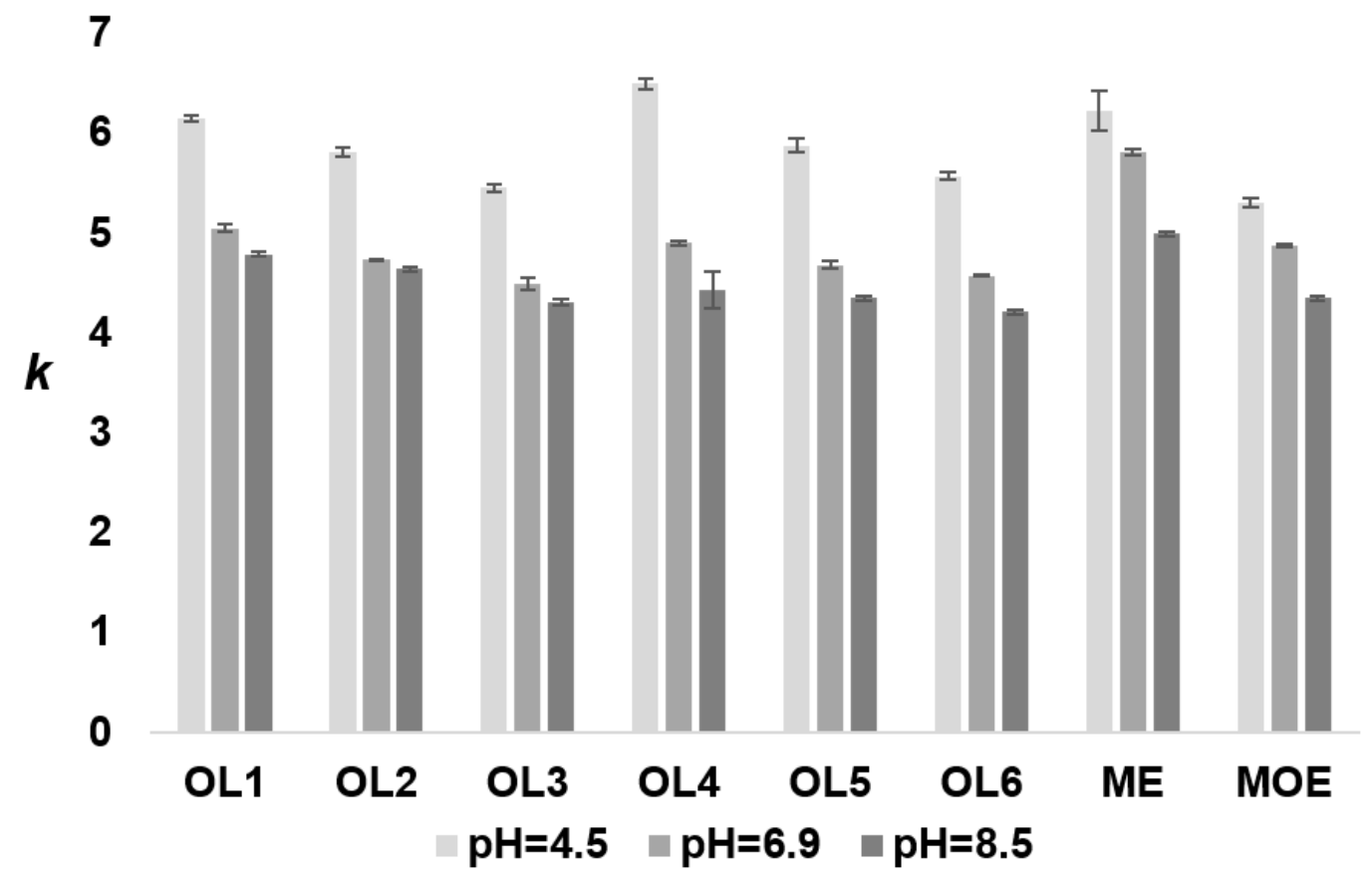

Figure 2. The impact of sodium chloride $\mathrm{pH}$ on the oligonucleotides' retention. Experimental conditions: stationary phase with III dendrimer layers; gradient elution program: 0 min $-0.125 \mathrm{M} \mathrm{NaCl}$, $5 \mathrm{~min}-0.4 \mathrm{M} \mathrm{NaCl}, 15 \mathrm{~min}-0.4 \mathrm{M} \mathrm{NaCl}$; flow rate $0.3 \mathrm{~mL} / \mathrm{min}$; autosampler and column temperature: $35^{\circ} \mathrm{C}$; injection volume: $1 \mu \mathrm{L}$; detection $\mathrm{UV}$ at $\lambda=260 \mathrm{~nm}$. 
Such trends were observed regardless of the oligonucleotide length and type of modification. Apart from quaternary ammonium groups, whose charge is $\mathrm{pH}$-independent, secondary and tertiary amines, with a positive charge at a lower mobile phase $\mathrm{pH}$, are also present in the stationary phase structure. The synthesis of dendrimer stationary phases is a multi-step process. Firstly, the surface of the silica gel is modified with propylamine groups and next with dendrimer groups. However, not all available aminopropyl groups are blocked during further synthesis steps; some will interact with the analyte. These weak ion exchangers remain open for the oligonucleotides during the chromatographic process.

Consequently, higher $k$ values at $\mathrm{pH}=4.5$ were determined (compared to higher $\mathrm{pH}$ ) due to the more significant number of protonated anion-exchange groups on the surface of the stationary phase (Figure 2). Nevertheless, it should be emphasized that as the $\mathrm{pH}$ value of the $\mathrm{NaCl}$ solution decreased, the oligonucleotide peak shapes became asymmetric $\left(\mathrm{f}_{\mathrm{AS}}\right.$ greater than 1.5). This effect was probably due to greater retention and interaction between the dendrimer surface and oligonucleotide. For this reason, a $\mathrm{pH}$ of 6.9 was selected for further studies.

In contrast, at $\mathrm{pH}=8.5$, a higher concentration of hydroxide ions is present in the solution. In ion chromatography, hydroxide ions have significant elution strength on anion exchangers. Thus, the increasing hydroxide anion concentration results in a decrease in retention compared to neutral $\mathrm{NaCl}$ solution. Additionally, it is necessary to emphasize that the pKa of secondary amine in the structure of bonded ligands is around 8. This confirms that a significant decrease in protonation in the $\mathrm{pH}$ range 6.9-8.5 was observed, and thus a reduction in the oligonucleotides' retention.

\subsection{The Impact of Dendrimer Layers on the Oligonucleotide Retention}

The last stage of oligonucleotide retention studies using dendrimer stationary phases was studying the effect of the number of anion-exchange layers on the retention of oligonucleotides, measured as $k$ values. The results are presented in Figure 3.

\section{6}

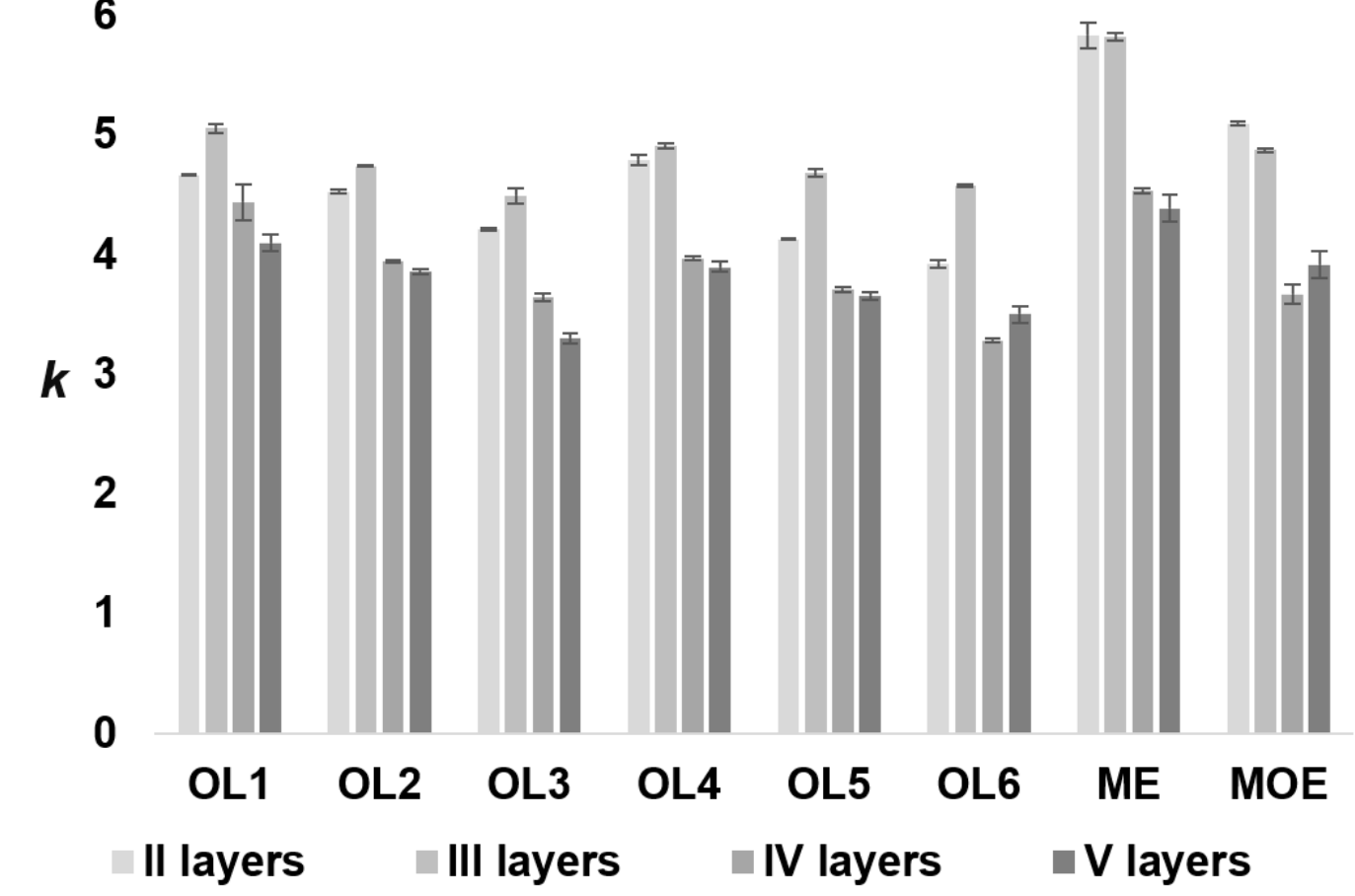

Figure 3. The influence of anion-exchange layers in the dendrimer structure of the stationary phases on the retention of oligonucleotides. Experimental conditions: gradient elution program: 0 min$0.125 \mathrm{M} \mathrm{NaCl}, 5 \mathrm{~min}-0.4 \mathrm{M} \mathrm{NaCl}, 15 \mathrm{~min}-0.4 \mathrm{M} \mathrm{NaCl} ; \mathrm{pH}=6.9$; flow rate $0.3 \mathrm{~mL} / \mathrm{min}$; autosampler and column temperature: $35^{\circ} \mathrm{C}$; injection volume: $1 \mu \mathrm{L}$; detection $\mathrm{UV}$ at $\lambda=260 \mathrm{~nm}$. 
An increase in retention was initially observed with an increasing number of anionexchange layers in the dendrimer structure of the stationary phase (Figure 3) for unmodified oligonucleotides (OL1-OL6), with the exception of ME and MOE. This trend concerns II and III layers of anion exchangers and is related to the greater number of $\mathrm{NR}_{3}{ }^{+}$groups on the surface of the stationary phase with three anion-exchange layers. The electrostatic interactions between this material and the oligonucleotides were more effective than the stationary phase with two anion-exchange layers. A further increase in dendrimer layers to four resulted in lower oligonucleotide retention (Figure 3). This results from the steric barrier formed due to greater ligand branching and the denser structure [16-20]. The decrease in $k$ for the stationary phase with IV and V anionexchange layers is due to the lower mass transfer of high-molecular-weight biomolecules in the dendrimer layers. Moreover, the $100 \AA$ pores at the silica surface are probably significantly obstructed when dendrimers with IV and V layers are synthesized. The observed effect is perhaps a consequence of two phenomena. Firstly, the penetration of oligonucleotides that are giant molecules between dendrimer branches to anionexchange sites is hampered. On the other hand, excluding oligonucleotides from the pores may also play a significant role for IV and V layers. It results in a decrease in retention. It is essential to underline that the highest decrease is observed between the III and IV bonded layers.

Further reaction cycles do not significantly reduce the retention. However, the exception was OL6 and MOE, for which the $k$ values increased slightly between layers IV and $\mathrm{V}$, indicating that perhaps the steric barrier effect is not critical for all tested oligonucleotides. Therefore, it is the general trend for macromolecular oligonucleotides and dendrimeric stationary phases. Summarizing, in the case of stationary phases with two and three layers, oligonucleotides penetrate branched ligands and interact with quaternary ammonium groups. This becomes difficult when the silica gel is modified with more anion-exchange layers. Therefore, it may be assumed that oligonucleotide retention on dendrimer anion exchangers is determined by two factors: electrostatic interactions with $\mathrm{NR}_{3}{ }^{+}$groups (main effect) and the ability to penetrate stationary phase layers (supplementary effect).

\subsection{Oligonucleotides' Mixture Separation Using Dendrimer Stationary Phases in Ion-Exchange Chromatography}

An attempt to separate two oligonucleotide mixtures (OL1, OL2, OL3, and OL4, OL5, OL6) was made for all tested stationary phases. The mobile phase was the same in the case of all tested mixtures. The decrease in OGN retention was noticed for dendrimers with IV and V layers because of the effects described in the previous section. Although greater retention was determined for V layers, the separation selectivity (especially between 10-mer and 15-mer) was greater for the anion exchanger with IV layers (Figure 4). This is a consequence of the steric hindrance between the oligonucleotide and stationary phase with branched five layers. Both stationary phases will not provide satisfactory results for oligonucleotide mixture separation. A similar conclusion may be drawn for the stationary phase with II anion-exchange layers. Complete separation of both mixtures was obtained for the adsorbent with III anion-exchange layers (Figure 4). It is likely that two effects play an essential role: a sufficient number of $\mathrm{NR}_{3}{ }^{+}$groups (allowing for effective electrostatic interactions) and low steric hindrance (allowing oligonucleotides to penetrate stationary phase pores). Our results indicate that sodium chloride and a dendrimer stationary phase with three layers are preferred for oligonucleotide separation.

The separation results are similar when comparing the two mixtures because of the samples' similar lengths of three oligonucleotides (10-mer, 15-mer, 20-mer) (Figure 4). As mentioned earlier, the retention of oligonucleotides on the dendrimer stationary phases in ion-exchange chromatography is based on the difference in their length (the net charge of the molecule is changing simultaneously). 


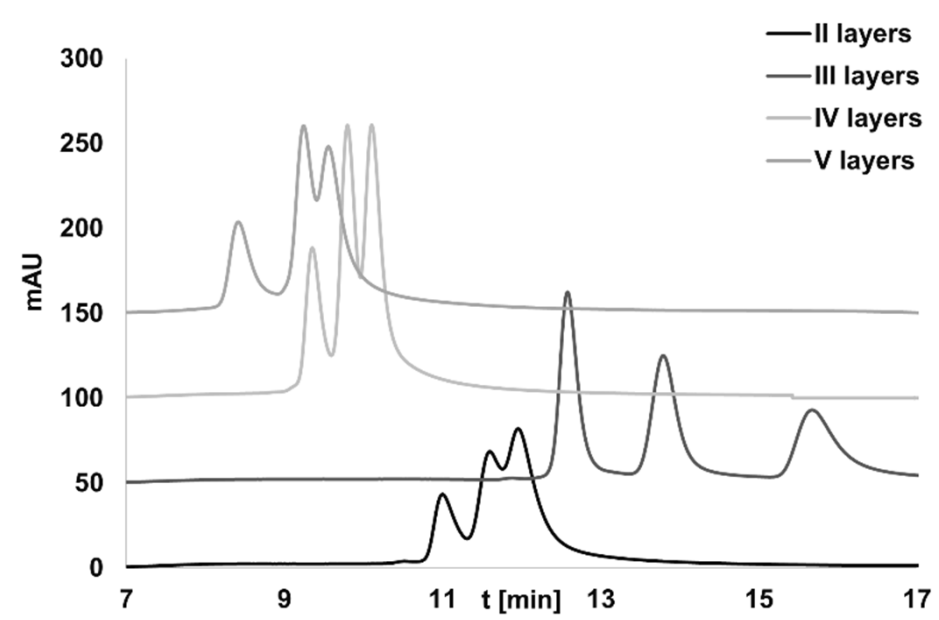

(A)

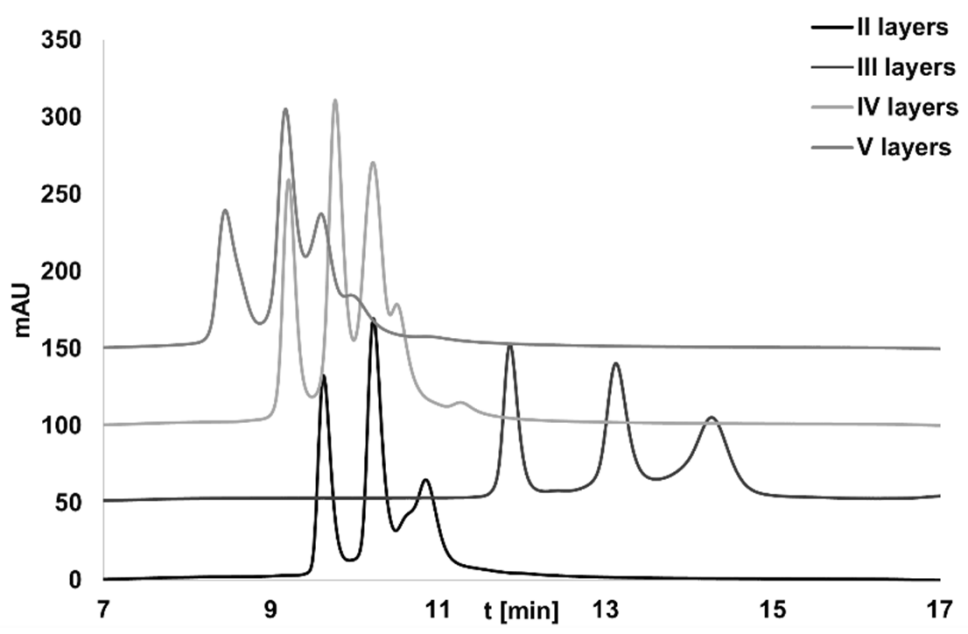

(B)

Figure 4. Separation of oligonucleotide mixtures using dendrimer anion exchangers: (A) mixture of OL1, OL2, OL3; (B) mixture of OL4, OL5, OL6. Experimental conditions: gradient elution program 0 min $-0.125 \mathrm{M} \mathrm{NaCl}, 5 \mathrm{~min}-0.4 \mathrm{M} \mathrm{NaCl}, 15 \mathrm{~min}-0.4 \mathrm{M} \mathrm{NaCl}$; $\mathrm{pH}$ 6.9; flow rate $0.3 \mathrm{~mL} / \mathrm{min}$; column and autosampler temperature $35^{\circ} \mathrm{C}$; injection volume: $2 \mu \mathrm{L}$; UV detection $\lambda=260 \mathrm{~nm}$; elution order for (A) OL3, OL2, OL1; for (B) OL6, OL5, OL4.

To summarize, the retention data reproducibility was good (relative standard deviations were lower than $15 \%$ ). The developed separation method determined the intraday and interday precision values (by analyzing oligonucleotide mixtures at two different concentration levels). The intraday precision was lower than $3.4-3.9 \%$ for low and $2.8-4.3 \%$ for high concentrations. The interday precision values were in the range of $3.5-4.8 \%$. The lifetime of the chromatographic column with III dendrimer layers was used for two months of daily operation (4 days per week for around $6 \mathrm{~h}$ per day) during the study. After this time, a slight tailing of peaks was observed, suggesting a slow loss of efficiency.

\section{Materials and Methods}

\subsection{Materials}

The anion exchangers were prepared by modifying silica gel Kromasil 100 (Akzo Nobel, Bohus, Sweden) with particle size $5 \mu \mathrm{m}$ and an average pore diameter of $100 \AA$. The specific surface area of bare silica gel was $313 \mathrm{~m}^{2} / \mathrm{g}$, and pore volume was $0.87 \mathrm{~cm}^{3} / \mathrm{g}$. The following reagents were used for the chemical modification of the silica gel support material: methylamine (MA40\% in water, $v / v$ ) and 1,4-butanedioldiglycidylether (BDDE $95 \%$ in water, $v / v$ ), both purchased from Sigma-Aldrich Chemie (Steinheim, Germany). 
The detailed synthesis procedure is described in the previous study [16-18]. Each reaction cycle provides the deposition of the following layer of the anion exchanger. Thus, the number of reaction cycles corresponds to dendrimer generation and bonded layers of anion exchangers.

In the previous studies, dendrimer ion-exchange stationary phases were stable in the $\mathrm{pH}$ range 3.0-9.0. The application of material at higher $\mathrm{pH}$ strongly reduces the column lifetime. During laboratory work, the reproducibility of the stationary phases at various reaction steps allows us to obtain an RSD lower than $10 \%$.

During the study, unmodified and modified oligonucleotides differing in modification types and length were applied. Both unmodified and phosphorothioate were purchased from Sigma-Aldrich (Gillingham, Dorset, UK), while oligonucleotides with 2'-O-methyl, 2'-O-methoxyethyl modifications were obtained from Eurogentec (Seraing, Liege, Belgium). Table 2 presents the sequences, molecular masses, and types of modifications of all studied compounds. The lyophilized solutes were dissolved in deionized water to the concentration of $100 \mu \mathrm{M}$, and next, they were diluted to a proper concentration.

Mobile phases were prepared using the following solvents: deionized water (Milli-Q system, Millipore, El Passo, TX, USA), and high-purity salts such as ammonium formate and ammonium acetate, sodium chloride, sodium perchlorate (Sigma-Aldrich, Gillingham, Dorset, UK). Salts were prepared by dissolving an appropriate amount in deionized water and adjusting the $\mathrm{pH}$ using sodium hydroxide (Merck KGaA, Darmstadt, Germany) or hydrochloric acid (Merck KGaA, Darmstadt, Germany). Before use, mobile phases were filtered through $0.2 \mu \mathrm{m}$ nylon filters (Supleco Analytical, Bellefonte, PA, USA).

\subsection{Apparatus and Chromatographic Conditions}

During the study, a liquid chromatograph from Shimadzu Prominence (Kioto, Japan), equipped with a quaternary pump, degasser, autosampler, column thermostat, and spectrophotometric diode-array UV-Vis detector (DAD), was used. The data were collected using LabSolution version 5.8 with a computer data acquisition station.

The oligonucleotide retention studies were performed using the following gradient elution program: $0 \mathrm{~min}-0.125 \mathrm{M}$ of salt, $5 \mathrm{~min}-0.4 \mathrm{M}$ of salt, $15 \mathrm{~min}-0.4 \mathrm{M}$ of salt. Four mobile phases were used to elute the oligonucleotides, namely sodium chloride, sodium perchlorate, ammonium formate, and ammonium acetate. Salt concentrations were in the range of $0.1-0.4 \mathrm{M}$. Fresh salt solutions were prepared daily. For these salts, the impact of three different $\mathrm{pH}$ values $(4.5,6.9,8.5)$ on the retention of oligonucleotides was tested. The $\mathrm{pH}$ was modified by the addition of $\mathrm{HCl}$ and $\mathrm{NaOH}$, respectively. The flow rate was $0.3 \mathrm{~mL} \cdot \mathrm{min}^{-1}$, while the temperature of the autosampler and column equaled $35^{\circ} \mathrm{C}$. The $\mathrm{UV}$ detection wavelength was selected as $\lambda=260 \mathrm{~nm}$, while the injection volume was $1 \mu \mathrm{L}$ of $25 \mu \mathrm{M}$ solutions.

The material under study was packed into $150 \mathrm{~mm} \times 2.1 \mathrm{~mm}$ PEEK columns. All columns were packed using a DT122 packing pump (Haskel, Burbank, CA, USA) under the pressure of $25 \mathrm{MPa}$.

\section{Conclusions}

One of the most critical parameters in analyzing oligonucleotides by liquid chromatography is the resolution. This is a consequence of peak symmetry and, what follows, the efficiency and selectivity of chromatographic columns. The results obtained for oligonucleotides often require changes and improvements of the chromatographic system. The most rapidly developing direction of research on oligonucleotides using liquid chromatography is the search for new stationary phases for their analysis. For the first time, in the present study, dendrimer stationary phases were used to analyze oligonucleotides. The presence of quaternary ammonium groups in their structures allowed for electrostatic interactions between them and negatively charged phosphate groups in the oligonucleotides' structures. Therefore, dendrimer stationary phases can be successfully used as an alternative to commonly applied packing materials in ion-exchange chromatography. The 
developed chromatographic method is characterized by adequate selectivity for oligonucleotides with differing sequence lengths.

Nevertheless, high inorganic salt concentrations in the mobile phase limit the applicability of mass spectrometry detection, while UV-Vis detection has lower sensitivity. For these reasons, the dendrimer stationary phase with three layers may be utilized to analyze oligonucleotide impurities formed during their synthesis. In this case, their concentration is high, and consequently, the method's high sensitivity is not required.

Author Contributions: Conceptualization, S.S.; methodology, S.S. and S.B.; investigation, A.K. and S.B.; data curation, A.K., S.S. and S.B.; writing-original draft preparation, S.S. and S.B.; writingreview and editing, S.S., S.B. and B.B.; supervision, S.S.; project administration, S.S.; funding acquisition, S.S. All authors have read and agreed to the published version of the manuscript.

Funding: Financial support was provided by the National Science Centre (Cracow, Poland) under the Sonata Bis project (2016/22/E/ST4/00478).

Institutional Review Board Statement: Not applicable.

Informed Consent Statement: Not applicable.

Data Availability Statement: Not applicable.

Conflicts of Interest: The authors declare no conflict of interest.

Sample Availability: Samples of the compounds are available from the authors.

\section{References}

1. Crooke, S.T.; Liang, X.H.; Baker, B.F.; Crooke, R.M. Antisense technology: A review. J. Biol. Chem. 2021, 296, 100416. [CrossRef] [PubMed]

2. Bennett, C.F. Therapeutic antisense oligonucleotides are coming of age. Ann. Rev. Med. 2019, 70, 307-321. [CrossRef] [PubMed]

3. Sharma, V.K.; Sharma, R.K.; Singh, S.K. Antisense oligonucleotides: Modifications and clinical trials. MedChemComm 2014, 5, 1454-1471. [CrossRef]

4. Rüger, J.; Ioannou, S.; Castanotto, D.; Stein, C.A. Oligonucleotides to the (gene) rescue: FDA approvals 2017-2019. Trends Pharmacol. Sci. 2020, 41, 27-41. [CrossRef] [PubMed]

5. Bonilla, J.V.; Srivatsa, G.S. Handbook of Analysis of Oligonucleotides and Related Products; CRC Press: Boca Raton, FL, USA, 2011.

6. Studzińska, S. Review on investigations of antisense oligonucleotides with the use of mass spectrometry. Talanta 2018, 176, 329-343. [CrossRef] [PubMed]

7. Cook, K.; Thayer, J. Advantages of ion-exchange chromatography for oligonucleotide analysis. Bioanalysis 2011, 3, 1109-1120. [CrossRef] [PubMed]

8. Sun, J.; Joshi, D.; Betancourt, F.; Solodinin, A.; Woodland, B.; Yan, Y. Anion exchange chromatography of oligonucleotides under denaturating conditions. Nucleosides Nucleotides Nucleic Acids 2020, 39, 818-828. [CrossRef] [PubMed]

9. Thayer, J.R.; Puri, N.; Burnett, C.; Hail, M.; Rao, S. Identification of RNA linkage isomers by anion exchange purification with electrospray ionization mass spectrometry of automatically desalted phosphodiesterase-II digests. Anal. Biochem. 2010, 399, 110-117. [CrossRef] [PubMed]

10. Thayer, J.R.; Wu, Y.; Hansen, E.; Angelino, M.D.; Rao, S. Separation of oligonucleotide phosphorothioate diastereoisomers by pellicular anion-exchange chromatography. J. Chromatogr. A 2011, 1218, 802-808. [CrossRef] [PubMed]

11. Totsingan, F.; Rossi, S.; Corradini, R.; Tedeschi, T.; Sforza, S.; Juris, A.; Scaravelli, E.; Marchelli, R. Label-free selective DNA detection with high mismatch recognition by PNA beacons and ion exchange HPLC. Org. Biomol. Chem. 2008, 6, $1232-1237$. [CrossRef] [PubMed]

12. Nesterenko, E.P.; Nesterenko, P.N.; Paull, B. Zwitterionic ion-exchangers in ion chromatography: A review of recent developments. Anal. Chim. Acta 2009, 652, 3-21. [CrossRef]

13. Żuvela, P.; Skoczylas, M.; Jay Liu, J.; Baczek, T.; Kaliszan, R.; Wong, M.W.; Buszewski, B. Column characterization and selection systems in reversed-phase high-performance liquid chromatography. Chem. Rev. 2019, 119, 3674-3729. [CrossRef] [PubMed]

14. Kubań, P.; Dasgupta, P.K.; Pohl, C. Open Tubular Anion Exchange Chromatography. Controlled Layered Architecture of Stationary Phase by Successive Condensation Polymerization. Anal. Chem. 2007, 79, 5462-5467. [CrossRef]

15. Pohl, C.; Saini, C. Determination of inorganic anions in environmental waters with a hydroxide-selective column. J. Chromatogr. A 2008, 1213, 37-44. [CrossRef]

16. Buszewski, B.; Jaćkowska, M.; Bocian, S.; Kosobucki, P.; Gawdzik, B. Functionalized polymeric stationary phases for ion chromatography. J. Sep. Sci. 2011, 34, 601-608. [CrossRef] [PubMed]

17. Jaćkowska, M.; Bocian, S.; Buszewski, B. Dendrimer modified silica gel for anion exchange chromatography: Synthesis, characterization and application. Analyst 2012, 137, 4610-4617. [CrossRef] [PubMed] 
18. Jaćkowska, M.; Bocian, S.; Gawdzik, B.; Grochowicz, M.; Buszewski, B. Influence of chemical modification on the porous structure of polymeric adsorbents. Mater. Chem. Phys. 2011, 130, 644-650. [CrossRef]

19. Bocian, S.; Studzinska, S.; Buszewski, B. Functionalized anion exchange stationary phase for separation of anionic compounds. Talanta 2014, 127, 133-139. [CrossRef] [PubMed]

20. Studzińska, S.; Rola, R.; Buszewski, B. Determination of nucleotides in infant milk formulas using novel dendrimer ion-exchangers. J. Chromatogr. B 2014, 945, 87-93. [CrossRef] [PubMed] 